AROUEOLOGía Y SOCIEDAD

№ 28, 2014: $305-320$

ISSN: 0254-8062

RECIBIDO: MARZO DE 2014

ACEPTADO: SETIEMBRE DE 2014

\title{
DUCCIO BONAVIA BERBER
}

(†4 DE AGOSTO DE 2012)

\author{
JUAN JOSÉ YATACO CAPCHA \\ Curador lítico del MUSEO de ARQUeología y ANTRopología, UNMSM \\ capchajuan@gmail.com
}

\section{RESUMEN}

Duccio Bonavia, profesor humanista, ha dejado innumerables obras científicas de vital importancia para la arqueología peruana. El presente «in memoriam» rinde un homenaje y destaca la personalidad del digno maestro. Una serie de comunicaciones personales, correspondencia con Ernesto Tabío e investigaciones, hoy pocas veces citadas, son brindadas para explicar algunos hechos importantes en la historia de este destacado investigador de la arqueología peruana.

PalabRas Clave: Duccio Bonavia, arqueología peruana, Universidad Nacional Mayor de San Marcos, Museo de San Marcos, Ernesto Tabío.

\section{Abstract}

Professor Duccio Bonavia contributed important scientific research to the Peruvian archaeology. This «in memoriam» paper aims to provide some historical data to show his personality in especial as a superlative and truly mentor. A series of personal communications, correspondence with Ernesto Tabío, and some further documents works are quoted to bring into life some important events occurred within the history of the archaeology of Peru.

KeYwords: Duccio Bonavia, peruvian archaeology, San Marcos University, San Marcos University Museum, Ernesto Tabío.

Duccio Bonavia, de nacionalidad italoperuana, nació el 27 de marzo de 1935 en Spalato, cerca de la ciudad de Salona, en Dalmacia (hoy Croacia). Sus padres fueron Aurelio Bonavia y Neda Berber. Llegó al Perú el 28 de julio de 1949 y estudió en el colegio Antonio Raimondi, lugar en donde aprendió el castellano (Silva 2007: 39 ).

Labor complicada la de dar a conocer sus trabajos científicos más importantes, ya que Bonavia incursionó en diversas disciplinas, por lo que se hace difícil abordar su desenvolvimiento académico en este pequeño homenaje.

En primer lugar es vital hablar de su personalidad, pues una serie de hechos la resalta. Quiero destacar el trato de respeto y rectitud de profesor a estudiante; claro ejemplo se refleja en su preocupación y consejos para que el autor de la presente obra, lea los libros clásicos de arqueología 


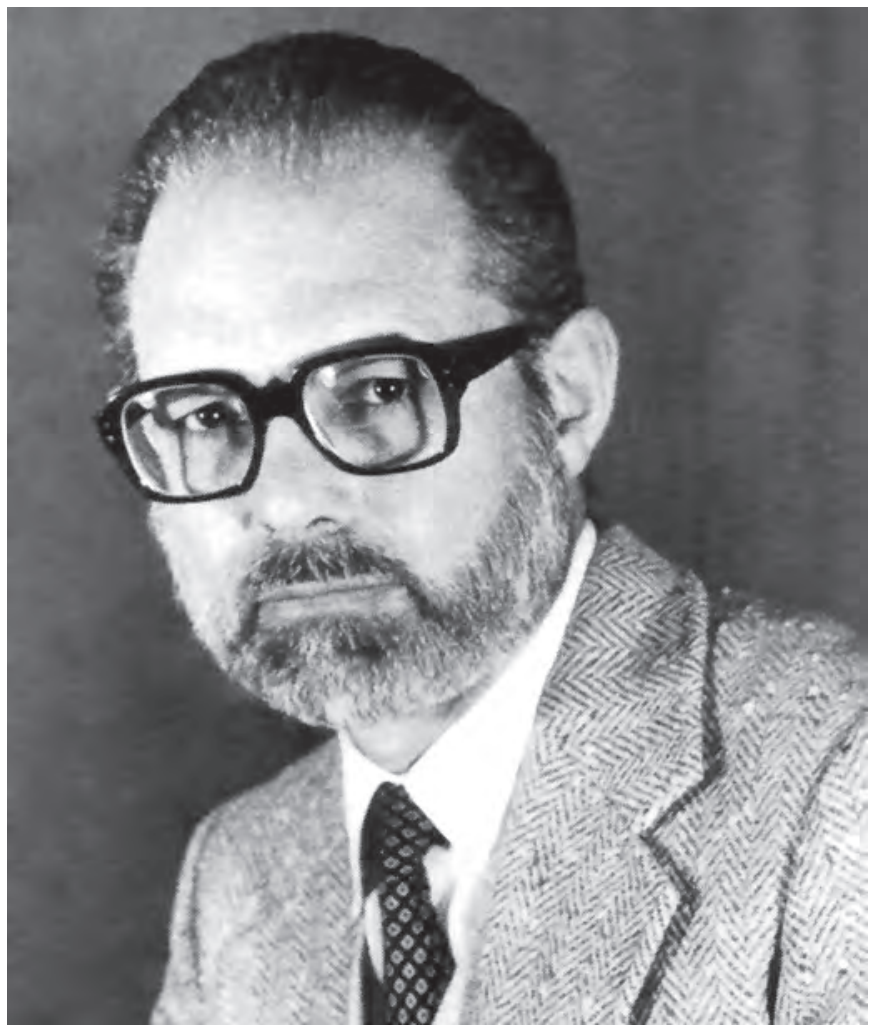

Duccio Bonavia Berber (1935-2012).

y así poder abordar con claridad temas específicos. Segundo, soy testigo de su admiración por Alfred Kroeber. Testimonio del profundo respeto que le tenía al antropólogo Kroeber, concreta en una conferencia sustentada en la Facultad de Letras de la UNMSM, titulada Alfred Kroeber y su obra peruanista, publicada en una nota necrológica en la Revista del Museo Nacional, tomo XXIX (Bonavia 1960). Cito textualmente:

«A partir de 1901 Alfred Kroeber comienza a interesarse en nuestra arqueología. Con él se inicia la obra de la Escuela de California, la única que se practicó en forma continua en nuestro medio y con metas muy concretas. Empieza con el estudio de las colecciones de Uhle, que lleva a cabo solo o con la colaboración de Gayton y Strong y se hace muy difícil, a partir de entonces, sintetizar su producción a nivel teórico o la que realizó sobre el terreno. Es él quien introduce el método tipológico en nuestra arqueología. Pienso que los dos ápices de sus contribuciones al Perú son primero su famosa conferencia de 1942 dedicada a los métodos de la Arqueología Peruana. Fue una intervención verdaderamente iluminante, que sigue de actualidad y que deberían leer con gran humildad las nuevas generaciones de nuestros alumnos. Y luego su libro Peruvian Archaeology in 1942 (1944) que marca hitos, deja enseñanzas y que no ha tenido igual posteriormente. Con su muerte, en 1956, desaparece el último antropólogo completo, el último humanista de la arqueología americana. Rowe ha sido el postrer representante de esta Escuela en los Estado Unidos. Con la desaparición de Muelle, el único que queda de esta tendencia en el Perú, es el que les habla» (Bonavia 2005-2006: 148).

Bonavia fue uno de los fundadores y organizadores de La semana de Arqueología, obra que los alumnos sanmarquinos han heredado. -Esta semana arqueológica que se celebra cada año en la UNMSM; 
lamentablemente está perdiendo su real esencia: lo académico-. Se organizó por primera vez en 1959; y tenía el nombre de Semana de Arqueología Peruana. A la inauguración asistieron grandes investigadores; contó con el aliento desde Estados Unidos de Alfred Kroeber (Bonavia 1959: 11). En este primer evento, Jorge Muelle disertó sobre el concepto de estilo en la arqueología peruana; Dorothy Menzel, de La Universidad de California, presentó un bosquejo del panorama de la arqueología de esos años; el aún estudiante Luis Lumbreras expuso también sobre el panorama de la arqueología peruana, pero enfocado en la solución de la cronología total del Perú en función de las áreas culturales. Emilio Choy participó con el tema de la revolución neolítica y los orígenes de la civilización peruana. Frédéric Engel y Augusto Cardich abordaron la época precerámica y los métodos de datación. Isabel Flores y José Casafranca pusieron en evidencia nuevos sitios de la sierra y a los que por aquellos años se les denominaba chavinoides. También se discutió sobre el estilo Nasca, a cargo de John Rowe y Lorenzo Rosselló. Edward Lanning, a partir de los trabajos de David Kelley y Paul Tolstoy brindó una visión panorámica de la arqueología de Piura que por esos años recién empezaba a investigarse. Toribio Mejia Xesspe disertó sobre el norte del litoral peruano, insinuando relaciones con el Ecuador. Gary Vescelius, brindó datos preliminares de sus investigaciones de la costa del extremo sur. El chileno Percy Dauelsberg, proporcionó datos de ocupaciones en el valle de Azapata, cerca de Arica. El boliviano Ibarra Grasso intentó una comparación regional entre los materiales arqueológicos precerámicos del Altiplano con los de Lauricocha. Trabajos descriptivos fueron realizados por Alejandro Pezzia, Ramiro Matos, Hernán Amat, Máximo Neira y José Fernández. También participó Francisco Iriarte, quien trató de definir el estilo local del valle de Lima. La Universidad Católica también se hizo presente con el trabajo que empezaba a realizar en la Tablada de Lurín. Gary Vescelius trabajó metodología arqueológica. El tema de antropología física estuvo a cargo de monseñor Pedro Villar Córdova; y el tema de análisis textil, a cargo de Fidel Untiveros (Bonavia 1959: 11). Más tarde a cargo de Ramiro Matos la semana de arqueología fue publicado con el título: «Antiguo Perú espacio y tiempo» (1960).

Es importante meditar las palabras de clausura de ese evento, celebrado en 1959, pues es el ejemplo que deben de seguir hoy en día estudiantes y profesores. Sobre el cierre del evento Bonavia escribió lo siguiente:

«Debemos ahora referirnos concretamente al discurso de clausura improvisado por el doctor Muelle y que tiene un hondo significado para nosotros, alumnos de arqueología de San Marcos. A nuestro entender las palabras de Muelle marcan una época en la arqueología nuestra y al mismo tiempo marcan un paso decisivo en la mutua comprensión entre el profesor y el alumno. «En esta oportunidad - dijo Muelle- los alumnos se han portado con plena aceptación del papel que les corresponde y nos han demostrado que quieren aprender dando así un mentís a las teorías pesimistas y de descargo que hemos forjado precisamente quienes tenemos, por nuestra edad y la función encomendada, la responsabilidad de guiarlos. Los que crean todavía que son los alumnos la causa del desorden de nuestra Universidad, no se han detenido en mirar la realidad o lo han hecho con pasión. La generación que llega no puede ser culpable de ese debilitamiento de las normas que caracteriza nuestros tiempos». Y más adelante añadió: «Los alumnos, pues, no solo concibieron la Semana de Arqueología, sino que la plasmaron en la halagadora realidad que nos ha devuelto la fe en la juventud». (Bonavia 1959: 11).

Y continuó lo siguiente:

«Para los que siempre hemos creído que la universidad está hecha para el estudio, sólo para el estudio, al margen de intereses bajos que hoy se denominan "política», estas palabras son muy halagadoras y nos honran de sobremanera. Nos honran porque nos dicen que en algo positivo hemos empleado los primeros e inestables esfuerzos de nuestra vida y que la primera etapa ha sido superada. Nos henchimos de orgullo al pensar que algo constructivo hemos hecho para la arqueología nacional tanto tiempo postrada y olvidada. Y si estos modestos esfuerzos han sido capaces de «devolver la fe en la juventud» a nuestros profesores, sea esto 
de agradecimiento a ellos a quienes debemos nuestra formación científica. Somos conscientes de la tremenda responsabilidad que adquiere todo aquel que se encamina en la senda de la arqueología; senda nueva en el Perú y por eso llena de espinas. Pero también sabemos de los frutos que los resultados pueden dar en beneficio del país y por eso seguimos adelante, a pesar de sacrificios e incomprensiones pensando que nosotros podemos también dar nuestro contributo a la arqueología peruana, y convencidos al igual que Muelle que «el Perú no desaparecerá nunca como nación, gracias a que su historia se hunde en un pasado remotísimo para extraer de allí la savia de una confianza en el futuro». Esa «savia» son los resultados halagadores de la Semana de Arqueología que acaba de realizarse en San Marcos» (Bonavia 1959: 11).

Estas palabras deben ser evaluadas por las actuales generaciones y ver si la formación arqueológica que reciben está encaminada con rigor científico. Y más aún si los alumnos tienen la debida vocación para ejercer esta profesión.

En 1960 Bonavia publica uno de sus trabajos que en el presente es un clásico de la arqueología peruana: Una Pintura Mural de Pañamarca, valle de Nepeña, editado por el Instituto de Investigaciones Antropológicas del Museo Nacional de Antropología y Arqueología (Bonavia 1959: 21-53). Este trabajo inaugura posteriores publicaciones sobre el tema de pintura mural: Ricchata Quellccani. Pinturas murales prehispánicas (Bonavia 1974); más tarde, una revisión ampliada de este, Mural Painting in Ancient Peru (Bonavia 1985).

No podemos dejar de mencionar un artículo de divulgación que paradójicamente ha sido marginado y es pocas veces abordado en las aulas universitarias: «Decoraciones murales de la vieja Lima» fue publicado en el suplemento dominical de El Comercio, con fecha 2 de diciembre de 1962 (Bonavia 1962: 6-7). Es un documento importante sobre dos murales ya desaparecidos. El primero es un panel en bajo relieve encontrado en uno de los montículos del conjunto de Mateo Salado. El segundo: restos de una pintura mural que se localizaba en los alrededores de la Huaca Aramburú. Esto fue otro esfuerzo de Bonavia por la preservación de las pinturas murales que nuestra generación no ha tenido el deleite de heredar. Creo pertinente citar algunas de las palabras de Bonavia, pero para ello alerto a los lectores que hay que ponernos en el contexto de la época: fueron escritas en respuesta al artículo «Las decoraciones murales y el deber de preservarlos» (Rosa Fung, El Comercio, enero de 1963); Bonavia escribió lo siguiente:

«Cuando los aficionados y los curiosos saben de la existencia de una pintura mural antigua, no hay defensa posible contra ellos, en las circunstancias actuales. Quizá las pocas que se han conservado son las de un templo con pinturas, excavado por Stumer en el valle de Chillón que, después del estudio fue cubierto, y una pintura descubierta por Uhle en Cerro Trinidad (Valle de Chancay), y que permanece aún cubierta. Richard Schaedel puso en práctica el sistema de cubrir las pinturas en Pañanarca (valle de Nepeña) infructuosamente, ya que hoy están al aire y destruyéndose. El último friso descubierto por unos turistas y que con la ayuda de la UNESCO pudo ser estudiado por el personal del Museo de Arqueología de San Marcos... no alcanzó a ser cubierto debido a su ubicación, ya que quedaba a $4.50 \mathrm{mts}$., sobre el nivel del piso actual, y el costo de un trabajo similar de protección no se pudo financiar. Las autoridades tampoco han intervenido, a pesar de habérseles informado. El mismo equipo de San Marcos tiene ubicadas una serie de pinturas en el mismo conjunto de Pañanarca y no se ha decidido estudiarlas, justamente por el hecho de que mientras permanezcan cubiertas estarán preservadas». (Bonavia, El Comercio, Lima, 14 de enero de 1963, pp.2).

Como todo estudiante en arqueología, ignoraba muchos de los trabajos de Bonavia; grande fue mi sorpresa al ir registrando y leyendo sus publicaciones. Obras que en mis clases de estudiante ni se mencionaban; mucho menos se realizaron revisiones críticas de sus investigaciones.

Ahora, permítaseme referirme de aquí en adelante a Duccio Bonavia en términos personales, como alumno, con el mayor respeto y seriedad que merece. 
Conocí a Bonavia a mediados de 2003, cuando me encontraba cursando mis dos últimos años de carrera universitaria. Elmo León, quien regresaba de obtener su $\mathrm{PhD}$ en Alemania, me invitó a buscarlo. Me acerqué a él para que me orientara en un trabajo que en ese momento yo realizaba en un sitio del Horizonte Tardío, ubicado en el valle Medio del Chillón. Le pedí una cita y pude conocerlo en su oficina de la Universidad Cayetano Heredia. Como todo alumno, acudí con cierto temor. Nunca olvido lo primero que hizo: miró mi trabajo buscando el final de mi manuscrito y revisó atentamente la bibliografía. No recuerdo con claridad todas sus preguntas. Pero hizo que le explicara algunos datos concretos sobre la tesis que había consultado del investigador Tom Dillehay (Dillehay 1976). Han pasado 10 años y entiendo perfectamente el actuar del maestro, pues es de sumo rigor el control bibliográfico, exigencia científica que aprendió Bonavia de sus maestros Raúl Porras Barrenechea y Jorge Muelle. En su oficina pude examinar algunas de las colecciones líticas del valle de Huarmey que él había recuperado en sus trabajos de prospección y que están publicados en Los Gavilanes: Mar, desierto y oasis en la historia del hombre (Bonavia 1982). No recuerdo cuántas veces más acudí donde él, quien llevaba a su oficina los libros Prehistoric Settlement Patterns in The Virú Valley (Willey 1953), y La tipología clásica europea del Paleolítico Inferior y Medio (Bordes 1981). También revisamos parte de su colección lítica europea con la lista tipológica del Paleolítico Superior de madame Bordes (Sonneville-Bordes et al. 1954-1956). Ésta la adquirió de manos de François Bordes y pudo completarla gracias a Jacques Pelegrin. Sin lugar a dudas, la enseñanza de Bonavia sobre la fabricación de raspadores, la preparación de buriles y la tecnología lítica, fue enriquecedora.

Es necesario recordar a los estudiantes que Bonavia ha sido el único profesional que ha publicado todos los materiales arqueológicos que ha recuperado en campo, sin adeudar alguna publicación, ejemplo digno que todo alumno debe de aprender desde las aulas universitarias.

Otro hecho que considero importante fue cuando Bonavia dejó la Universidad Cayetano Heredia. Si bien era una persona muy seria y trataba de no demostrar su lado más sensible, su rostro reflejaba el sumo dolor que le causaba dejar las aulas universitarias. Debido a esto empecé a acudir a su hogar desde 2004, el que tornó mi segundo hogar, hasta su retiro de nuestro país en marzo de 2011. Es en su casa dónde él dejó que tomara una decisión personal. Recuerdo claramente que me esperaba una tarde con un par de libros sobre su mesa y sentado frente a mí, me dijo lo siguiente:

«Hay algo que usted debe de saber para que pueda seguir viniendo a mi casa: primero, conmigo se trabaja con la verdad; no me gustan las mentiras. Segundo, si usted busca que la arqueología le brinde fama y fortuna no la encontrará aquí. La arqueología que realizo no es la de buscar reconocimientos, ni salir en la televisión, mucho menos me da dinero; yo me dedico a trabajar en silencio, de la manera más seria y difícil. Usted vea qué elige. Si su elección es trabajar de manera seria, vuelva a buscarme y le ayudo en lo que desee».

Pasé unos días meditando sus palabras, pues es en esos años, a finales de mi carrera universitaria, ya se planificaban las salidas de campo a proyectos de investigación, los trabajos para programas de reconocimiento arqueológico; en ocasiones se extendían invitaciones para formar parte de programas de evaluaciones arqueológicas pagadas; estaban en desarrollo los trabajos del Cápac Ñan y los famosos proyectos de rescate arqueológico, que requerían de personal para distintos trabajos de campo y laboratorio. Tengo la satisfacción personal de haber elegido el camino largo y difícil de la arqueología.

Es conveniente que los estudiantes de arqueología entiendan que el trabajo en silencio, con humildad y con la verdad en las manos, tiene un lado satisfactorio que se torna invaluable. Estoy convencido de que no hay mejores palabras que las de Bonavia para explicarlo: «[...] la más grande satisfacción que puede tener un arqueólogo y que vale más que cualquier dinero, es ver publicada su obra pero más que eso y sobre todo verse citado en la bibliografía de los demás colegas y darse cuenta que lo que se hizo ha sido útil en el campo de la reconstrucción de nuestro pasado» (ms. Bonavia, Trujillo 28 de febrero del 2011). 
La oportunidad de trabajar a su lado se presentó años más tarde, en el 2007, cuando se encontraba realizando la investigación sobre el maíz. Fue ahí cuando pasamos largas horas en su casa realizando la revisión bibliográfica de su libro (Bonavia 2008). A partir de este trabajo observé de cerca su rigurosidad y control de las citas bibliográficas. También aprendí cómo organizaba la información, la búsqueda minuciosa de las publicaciones arqueológicas, y el uso metódico y riguroso de las fichas bibliográficas.

Hay una serie de opiniones de algunos colegas que recuerdan a Bonavia como una persona intolerante; yo no comparto esas opiniones. Es más, atestiguo una serie de hechos que guardo con mucho cariño y que desmienten esas apreciaciones. Su carácter ha sido siempre el correcto y el trato de profesor a estudiante ha sido de mutuo respeto. Sé que Bonavia no toleraba la conducta criolla y sobre todo el obtener algo de manera irregular. Reitero que la honestidad y la verdad han sido los lemas con los cuales ha trabajado toda su vida. Sin temor a equivocarme puedo decirles que cuando Bonavia mostraba un trato duro con alguien era por un buen motivo. Soy testigo de cómo él quitaba su amistad al hallar algún engaño o simplemente se enteraba de primera mano y con detalles del trabajo deshonesto de alguna persona. Además, su actitud sumamente crítica y severa, desde mi punto de vista, ha sido siempre la correcta, pues cuando pedía leer un libro específico, sabía del contenido, y más de una vez me ha explicado con lujo de detalles el por qué no se debía perder tiempo en uno y pasaba a recomendar otro, el cual brindaría mayor amplitud a la formación académica.

Bonavia podía llegar a brindar su amistad. Esta la gané cuando se enteró de que obtuve la licenciatura en 2008. Sé que para él era sumamente importante poder demostrar que con constancia, dedicación y planificación se logran objetivos propuestos. Recuerdo con mucha emoción cuando me citó en su casa para brindar por este éxito. Una tarde, luego de culminar las labores en el Museo de Arqueología y Antropología de la UNMSM (MAA-UNMSM), me esperó en su casa con unos libros y una larga charla sobre la crisis de la arqueología. A partir de nuestra conversación y a las preguntas que le hice me mostró su álbum de fotografías para ilustrarme los trabajos que se habían efectuado sobre una serie de yacimientos arqueológicos peruanos. Entre estos se encontraba Lauricocha y me explicó con lujo de detalles sobre la excavación que realizó el ingeniero Augusto Cardich y los problemas que presenta este sitio. También pude consultar un archivo de sus correspondencias personales que sostuvo con Ernesto Tabío, David Kelley, Edward Lanning y Terence Grieder, entre otros. De ahí en adelante nunca me habló con la seriedad que le caracterizaba.

El MAA-UNMSM resguarda un conjunto de bienes culturales arqueológicos que ameritan estudiarse en detalle. Debido al interés por recabar información de las colecciones clásicas, ha sido de gran ayuda la información que nos ha proporcionado Bonavia. Como era característico en él, respondía con una serie de datos que hoy guardo con celo. Es pertinente el momento para extenderles algunas de las comunicaciones personales. Esto con el fin de ilustrar a los estudiantes sobre algunos hechos de los que casi no quedan evidencias. El contexto es este: a mediados de 2011 en el MAAUNMSM nos planteamos como objetivo recuperar una serie de planos que estaban en mal estado de conservación. El trabajo fue fructífero: salvamos estos documentos. La sorpresa fue encontrar un par de dibujos deteriorados en papel milimetrado que personalmente me interesó, pues éste lleva la firma de Félix Caycho. Este plano es singular, pues se trata de los dibujos de planta del primer piso (№ 656) y segundo piso (№ 658) del viejo local de la Calle Zamudio, Hoy Jr. Cusco, (Figs. 1 y 2), en donde funcionó el antiguo Museo de Etnología y Arqueología de San Marcos. Sabiendo de la importancia de estos documentos y de la enorme amistad que tuvo Duccio Bonavia con Félix Caycho, redibujamos los planos. Bonavia se sorprendió de ello y nos explicó todo lo que recordaba. Hoy estos detalles forman parte de la historia de la creación del Museo de Arqueología y Antropología de la UNMSM y es mi deber el compartirlo con ustedes ${ }^{1}$.

1 Para entendimiento del lector he enumerado la comunicación personal de Bonavia, la cual se articula con las figuras 3,4 y 5. 


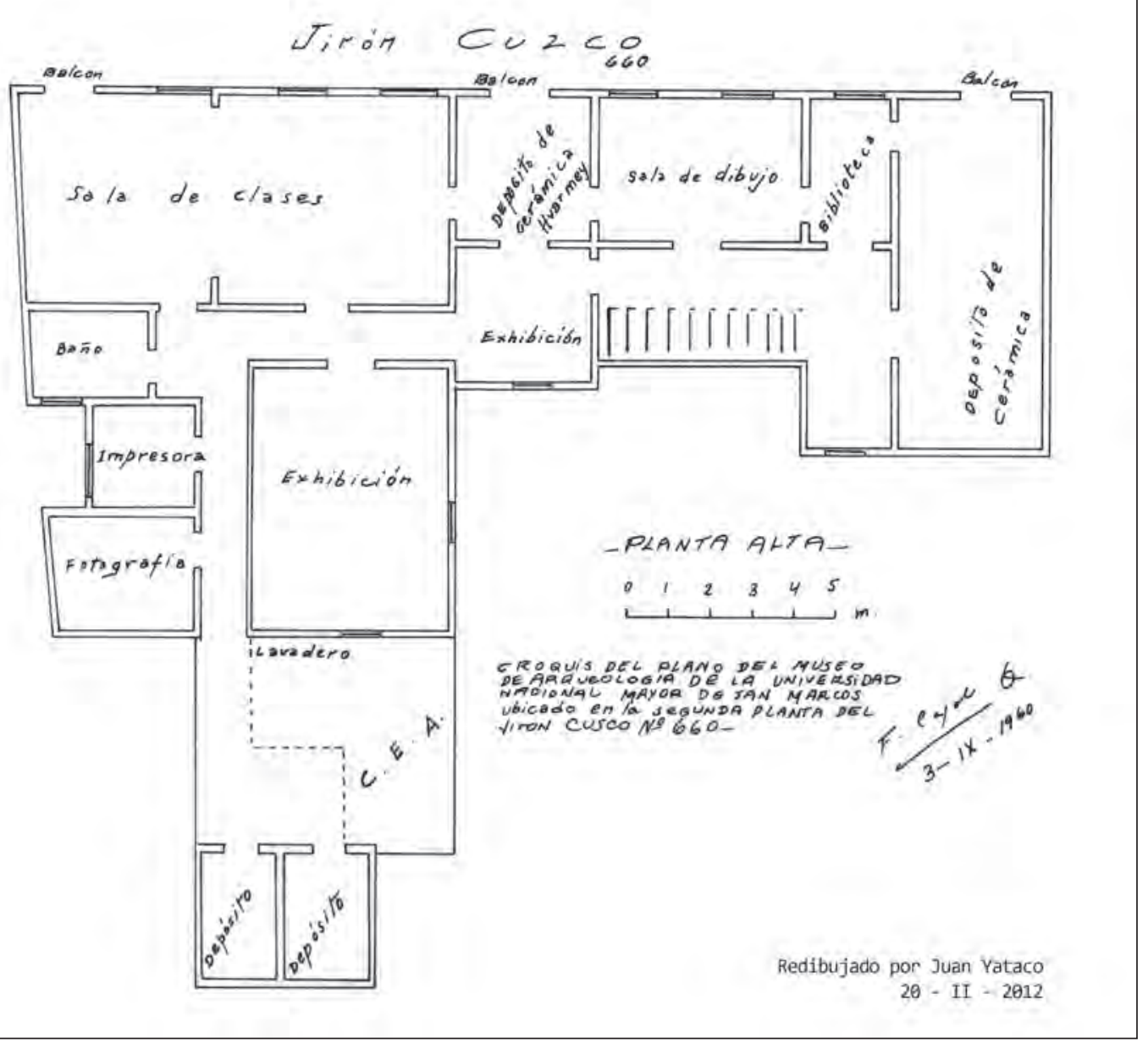

Figura 1.

Empezaré con la planta alta (Fig. 3); al respecto Bonavia dice lo siguiente:

«[...] en primer lugar me parece que el plano de Caycho refleja lo que se quiso hacer cuando José Matos creó el Museo, pero muchas cosas no se realizaron. 1. Depósito de cerámica. Ahí estaba toda la cerámica que se sacó del Museo Nacional de Antropología y Arqueología ${ }^{2}$ Estaban representados todos los estilos. 2. Lo que figura como biblioteca nunca fue biblioteca. Fue la oficina que utilizó Rosa Fung. 3. Lo que figura como sala de dibujo nunca fue eso. Al principio la utilizó Lumbreras como oficina, pero cuando bajó quedó para cualquiera que la necesitara. 4. Lo que figura como depósito de cerámica Huarmey nunca fue dedicado a eso. Esa fue la oficina de Caycho con su mesa de dibujo. De los dibujos, Caycho se encargaba. Pero además era prácticamente el Director a las órdenes de Matos Mar. 5. Frente al cuarto de Caycho había una pequeña exhibición, y la sala «exhibición» era la que figura como tal. Se hizo

2 Bonavia se refiere a las piezas arqueológicas que se recuperaron del Museo de Nacional de Antropología y Arqueología. Pues en ese momento se recuperó tan solo una parte de las colecciones que pertenecen a la Universidad Nacional Mayor de San Marcos. 


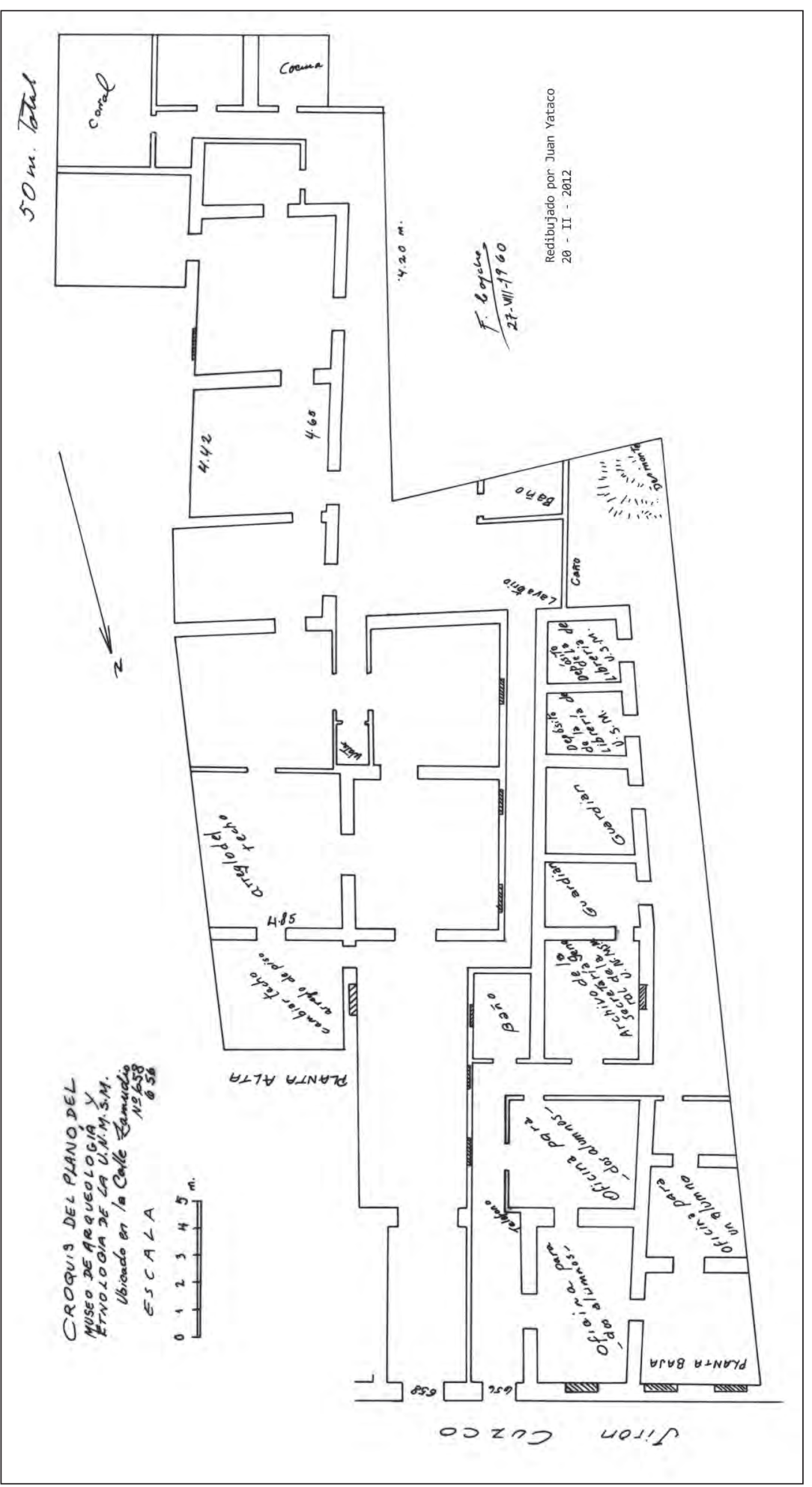

ปั่ 
antes de que yo llegara ahí, pero reunía las mejores piezas de cada cultura; predominaba sin embargo la Nasca. Si puedes ver el libro de Herman Buse de 1962, Perú 10,000 años, al costado de la pagina 201 me verás a mí en la sala de exhibición. 6. La sala de clases no tenía dos entradas sino solo una, la que está frente a la sala de exhibición. La otra fue clausurada y a lo largo de toda esa pared estaban depositadas las colecciones nuevas que llegaban. Ahí estaba lo relativo a Huarmey por ejemplo. Era al mismo tiempo sala de clases y sala de conferencias y reuniones. Ahí nació el Miércoles Arqueológicos, que nosotros hemos creado. 7. Impresora nunca hubo. Era un cuarto que servía como depósito. 8. Fotografía. Era un laboratorio completo que era utilizado por todos los que sabían manejarlo. A veces se prestaba el laboratorio; por ejemplo, María Reiche trabajó ahí. 9. Donde dice CEA (Centro de Estudiantes de Arqueología) en realidad no teníamos sede y nos reuníamos en San Marcos [hoy Centro Cultural de San Marcos]» (Bonavia, comunicación personal martes, febrero 28, 2012).

Sobre la planta baja, Duccio Bonavia me escribe lo siguiente (Figs. 4 y 5):

«1. Lo que tenía el № 658 nunca fue utilizado por el museo, y no recuerdo qué había ahí. 2. Nosotros utilizábamos sólo el № 656. En las dos oficinas de la izquierda, cerca del pasadizo, y en la que está en el fondo (donde dice planta baja), estaban Lumbreras, Guzmán Ladrón de Guevara y tres alumnas cuyos nombres no recuerdo. Ellas nunca hicieron nada serio y al terminar se retiraron de la Arqueología. Un tiempo en la oficina del fondo estuvo Eduardo Lanning. 3. Si sigues por el pasadizo se llega al baño. La oficina para alumnos, que está casi frente al baño, tuvo esa puerta cerrada. Luego, si sigues por el pasadizo hacia la derecha, la oficina pequeña era la mía y donde dice oficina para un alumno, estaba Ramiro Matos. La puerta de esa oficina con la que dice planta baja estaba clausurada. Si te fijas en el mismo libro de Buse que te mencioné, ahí aparece Ramiro con un cráneo en la mano en su oficina. Trabajábamos todos en mandil blanco. 4. Lo que dice archivo de la secretaria...era en realidad un depósito con publicaciones de San Marcos. Recuerdo que estaba la Historia de la Medicina. 5. Donde dice guardián, efectivamente vivía el guardián con su familia. 6. Los últimos dos cuartos que dice depósito... sinceramente no sé qué tenían. Creo que con esto te he explicado todo. Si tienes alguna duda, házmela saber» (Bonavia, comunicación personal martes, febrero 28, 2012).

Estos datos son importantes, pues no tenemos hasta ahora un libro dedicado a la historia de la arqueología peruana y mucho menos una publicación que explique con documentos la creación y cambios que ha sufrido el MAA-UNMSM. Estos testimonios de Bonavia y los dibujos de su mejor amigo y excurador del MAA-UNMSM, Felix Caycho, son importantes.

Luego, otro hecho de aclarar es la creación de los Miércoles Arqueológicos. Sobre su origen se han tejido varias versiones; quiero brindarles la referencia de Bonavia: Un 29 de marzo de 2012, habiéndose consultado las referencias sobre los Miércoles Arqueológicos, que se encuentra en el libro Memorias, de Valcárcel (Matos et al. 1981: 395-396) y en vista de que el Museo de Arqueología y Antropología estaba planeando ejecutar una exposición en honor a este intelectual, se le preguntó si bajo la dirección de Valcárcel se formaliza institucionalmente los Miércoles Arqueológicos. Su respuesta fue esta:

«En las Memorias de Valcárcel hay errores y ello es debido a que una parte ha sido escrita por José Matos. Por ejemplo, en la página 396 se dice que Ravines participó en lo de la Comisión Fullbright. No es verdad. En ese entonces Ravines ni siquiera era estudiante de San Marcos. En la misma página se deja entender que fue la Facultad la que instituyó los Miércoles Arqueológicos. Eso es mentira. Los Miércoles Arqueológicos los organizamos un grupo de estudiantes: Lumbreras, Matos, Fung, yo, Ladrón de Guevara y algunas chicas cuyos nombres he olvidado, pero que no hacían nada. Al principio, la idea era reunirnos todos los miércoles a las siete de la noche en el Museo y comenzar a discutir entre nosotros. Luego se fue formalizando pues comenzaron a asistir gente como Tabío y otros. Y terminó siendo una cosa tan bien organizada, que no había arqueólogo extranjero que llegara al Perú que no participara un miércoles 


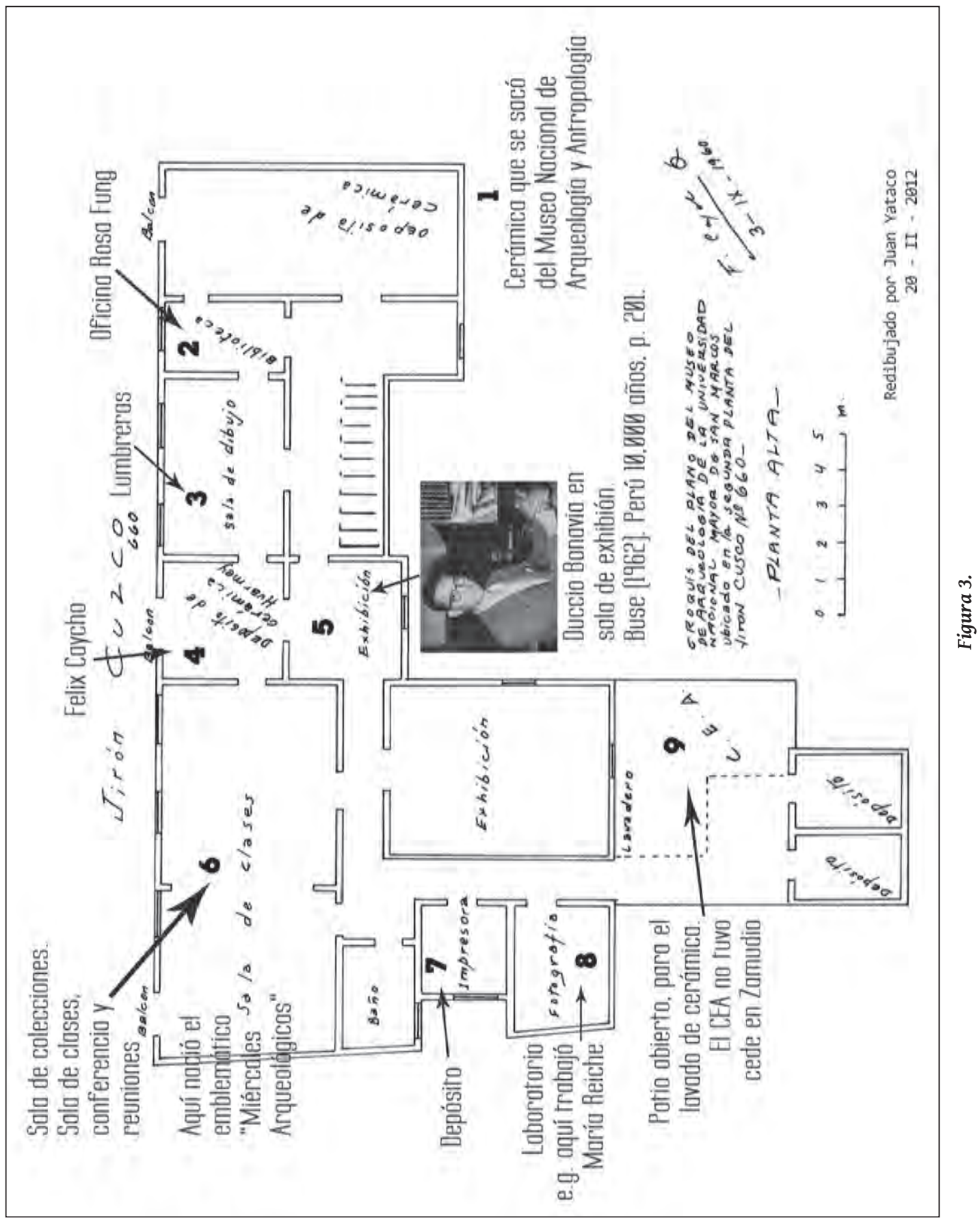




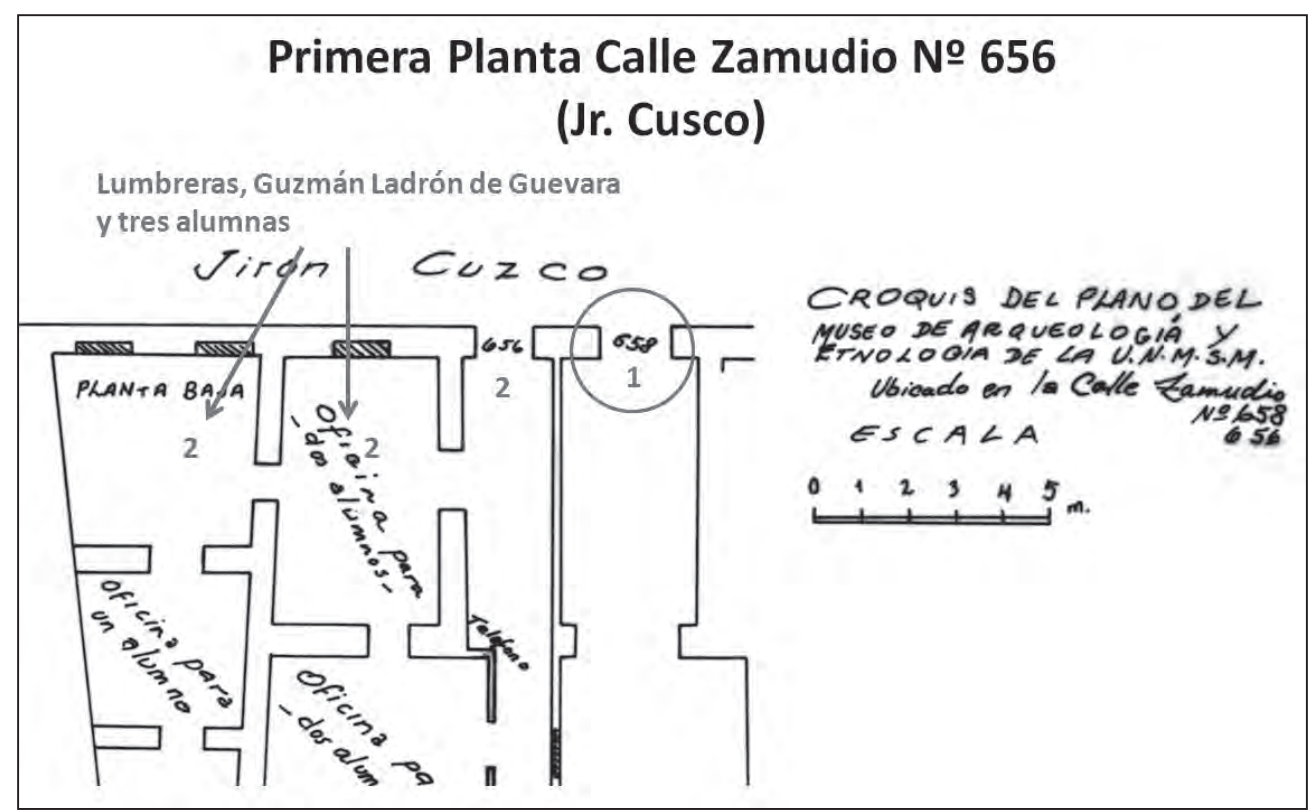

Figura 4.

\section{E. Lanning.}

Un tiempo trabaja en estááfesen $\quad C_{4} z C_{0}$

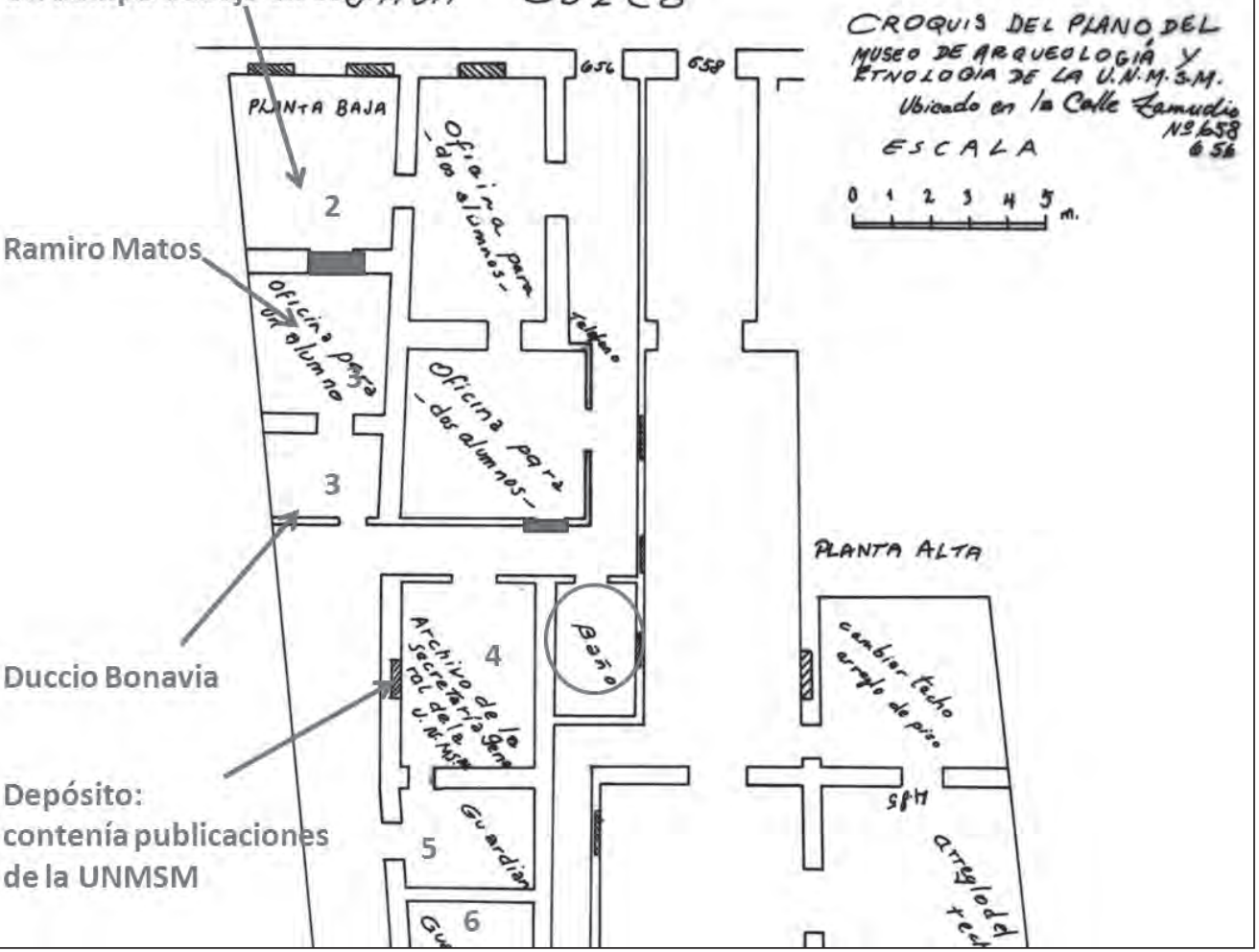

Figura 5. 
exponiendo. Además, nosotros como estudiantes también dábamos charlas explicando lo que estábamos investigando. En cierta manera, al final, el Miércoles Arqueológico se integró al CEA [Centro de Estudiantes de Arqueología], que también creamos nosotros con la Revista Cuadernos de la que yo fui uno de los directores. Si bien es cierto que eso se hizo cuando Valcárcel era Decano, la Facultad nada tuvo que ver con los Miércoles; sólo utilizábamos el local del Museo. Otra cosa que es grave, pues puede llevar a error, es que en la página 395-396 parece que San Marcos recuperó toda la colección que había depositado en el Museo de Antropología. Y no es verdad. Fue sólo una mínima parte. La colección de San Marcos sigue en el Museo [Museo Nacional de Arqueología, Antropología e Historia] y entre otras cosas está la Estela Raimondi, los mantos de Paracas, etc., etc., que San Marcos debería recuperar y podría armar un museo que le daría una entrada considerable» (Bonavia, comunicación personal, jueves 29 de Marzo de 2012).

La comunicación de Bonavia es certera y en estas líneas deja en claro su objetividad crítica y el manejo riguroso de los datos. Además, estoy de acuerdo con Duccio Bonavia, pues de crearse a futuro un Museo Universitario moderno que congregue las colecciones arqueológicas que pertenecen a La Universidad San Marcos sería una de las ideas más acertadas que podría concretar la máxima autoridad de la Universidad Nacional Mayor de San Marcos.

Ha sido un honor aproximar a Duccio Bonavia al MAA-UNMSM; una primera visita la realizó junto a Elmo León un lunes 10 de diciembre de 2007; recorrió nuestra sala de exposición y depósito de colecciones. Esto le trajo tantos recuerdos de su juventud y quedo asombrado del trabajo de conservación preventiva que venimos efectuando. Desde aquel momento se mantuvo siempre atento a los avances del museo. Luego participó en las celebraciones del noventa aniversario del MAA-UNMSM con la exposición «La domesticación de las plantas» (Bonavia 2010: 53-64). Otro ejemplo digno de seguir de Bonavia es su espíritu de colaboración para con el museo: más allá de que fueran sus colecciones, cuando le comunicamos que tuvimos problemas al congregar las colecciones de Ancón y de algunas piezas del estilo Teatino, envió al museo dos documentos importantes. Donó una copia del cuaderno que contiene valiosos dibujos de la cerámica del Estilo Teatino, con el cual realizó su tesis de bachiller (Bonavia 1960), así como una copia sobre el estudio del material arqueológico que recuperó del pozo estratigráfico PM de Ancón (Bonavia 1959). Estos valiosos documentos fueron entregados al área de colecciones del MAA en agosto de 2010. Estas dos copias son invaluables, pues debe entenderse que una colección arqueológica que no presenta su asociación estratigráfica se convierte prácticamente en obra de arte. El MAA-UNMSM custodia muchas colecciones; pero algunas de ellas no cuentan ni con la mínima referencia de los contextos estratigráficos ni publicaciones para poder orientarse en la contextualización e interpretación de los datos. Colecciones como las provenientes de las excavaciones de la Huaca San Marcos, Atrio de Chavín, Armatambo, etc., claman por ser contextualizados o al menos tener copias de las libretas de campo. Cuántos arqueólogos podrían ser sancionados o vetados de la práctica arqueológica si tan solo se revisaran en los museos nacionales o en gabinetes de distintos proyectos arqueológicos el estado de sus colecciones. O simplemente exigir a los mismos los documentos formales en dónde se detallen la entrega a los custodios de las libretas de registro de campo o los informes de excavación o simplemente se les solicitara las publicaciones de las mismas. Es un deber y un acto de profesionalismo brindar los datos contextuales para trabajar junto a los alumnos de esta casa de estudio las colecciones arqueológicas que permanecen en el olvido y que claman por publicarse.

No puedo pasar por alto una serie de correspondencias de Duccio Bonavia con uno de sus mejores amigos y que fechan entre 1960 y 1972. Me refiero al arqueólogo cubano Ernesto Tabío Palma, quien vivió en Lima entre 1953 y 1960. En estas cartas se emiten una serie de juicios personales de Ernesto Tabío; el objetivo de publicarlas en un futuro es revelar el suficiente interés, el profundo amor, la constante dedicación y el compromiso de ambos científicos por la arqueología de nuestro país. Permítaseme en este caso divulgar una correspondencia en dónde se puede comprender la profunda 
amistad y la devoción de ambos arqueólogos por la ciencia y confirmar con esto algunos hechos de los que he escrito anteriormente. Comparto la siguiente correspondencia de Tabío enviada a Bonavia, desde Cuba el 14 de junio de 1962: «Solo te diré que me siento muy orgulloso de ti como amigo y como hombre de ciencia, lo que tienes y tendrás te lo has ganado en una muy buena vida trabajando y poniendo toda tu alma en lo que haces [...]». Más adelante: «Sobre tu nombramiento como arqueólogo en el Museo de San Marcos, te envío mis más afectivas congratulaciones, te lo ganaste ya hace mucho tiempo, el Perú es el que gana con eso». (Correspondencia Tabío, Cuba 14 de junio de 1962).

Seguidamente, destacamos el inagotable interés de Tabío por la arqueología peruana manteniendo el constante contacto con colegas peruanistas y con su amigo Bonavia:

«[...] Por otra parte, me han designado profesor entre otros en un cursillo sobre Historia del Arte, que se está celebrando en nuestro Museo Nacional de La Habana, por supuesto sobre cultura prehispánica del Perú. Estas son actividades que uno no puede soslayar» [...] «vi tu intrepidez al explorar el área del Abiseo y Kuelap hasta en helicóptero... Salúdame a Muelle, Amano, Mejía, Rosselló, Choy, Caycho y Jiménez Borja. Como me gustaría poderlos ver a todos de nuevo, de verdad que el Perú lo recuerdo como mi segunda patria, cuando pienso en los ratos tan buenos que pasamos explorando la costa en mi Jeep, contigo o con Muelle, con el bueno de Horkheimer, qué recuerdos más gratos y amables» (Correspondencia Tabío, Cuba 18 de Octubre de 1966).

Para finalizar este punto, tengo que subrayar que Tabío Palma realizó una tesis arqueológica con materiales peruanos para sustentarla en Rusia (1969). En efecto, se trata de la única tesis donde se aplica con cautela y prudencia la teoría marxista a materiales arqueológicos peruanos provenientes de los valles de Casma, Huarmey y Fortaleza. Tengo que afirmar que esta es ignorada por los arqueólogos sociales peruanos e investigadores de otras corrientes teóricas que han realizado sus trabajos en estos valles.

Por otro lado, Duccio Bonavia deja una tremenda responsabilidad a todos quienes nos dedicamos a la arqueología; en especial, a las nuevas generaciones de arqueólogos peruanos. Me refiero al trabajo de enmendar el rumbo de la arqueología peruana, por el camino serio de la investigación y enfrentar la crisis que estamos viviendo. Tan solo tenemos que revisar algunas publicaciones y en especial un In memoriam dedicado a su amigo Fernando Silva Santisteban; en este Bonavia dice lo siguiente:

«En estos últimos años había un tema del que terminábamos hablando en forma recurrente, cambiando ideas por largas horas. Me refiero a la gran crisis que estamos viviendo. Crisis de valores, crisis de principios que ni él ni yo hemos podido aceptar. Se le desgarraba el alma al constatar la penosa situación en la que se encuentra nuestro patrimonio cultural y la total inopia del Estado frente a ello. Un Instituto Nacional de Cultura [hoy Ministerio de Cultura] que no cumple ningún rol. La situación trágica de nuestros museos. La pobreza en la que ha caído la enseñanza universitaria. Recordábamos ese gran esfuerzo que hizo José María Arguedas cuando fue director de la entonces Casa de la Cultura y que fue seguido por Fernando, para mejorar las cosas y que en buena parte se había iniciado y se estaba impulsando, hasta que con el gobierno militar [...] se produjo un vuelco totalmente opuesto a esa política y se dio inicio a la crisis de la que hoy aún sentimos los efectos y pagamos las consecuencias» (Bonavia 2007: 2).

Es de urgencia discutir el problema de la enseñanza de la arqueología; sobre este tema existe un libro que aborda con lujos de detalles la crisis que estamos viviendo. Me refiero a Enseñanza de la arqueología en el Perú, de FOMCIENCIAS, 1992. Aquí las encuestas realizadas por Duccio Bonavia y Ramiro Matos a los estudiantes, profesores y profesionales de distintas casas de estudio revelan lo caótico de la situación de la enseñanza arqueológica. San Marcos no queda excluida del problema. Quien consulte este libro notará que han pasado veintiún años desde su publicación y tenemos que preguntarnos si 
estamos evolucionando o involucionado en la enseñanza arqueológica. Es necesario y urgente platear soluciones serias que lleven al cambio sin mezclar en ella la «política» (el subrayado es mío). Quiero citar aquí unas cuantas líneas de este libro que deben meditarse, siempre poniéndonos en el contexto de la época en la cual fue publicada. Bonavia y Matos al respecto escriben lo siguiente:

«Es verdad que de parte del profesorado, salvo raras excepciones, hemos recibido el apoyo necesario y no hubo ninguna resistencia para someterse a nuestra encuesta. Sin embargo hay un hecho que no podemos soslayar. Hay un importante porcentaje de encuestados que han mostrado irresponsabilidad al contestar nuestras preguntas. En unos casos por negligencia o simplemente pereza para pensar, pero en otros por no tener la suficiente honestidad de admitir desconocimiento de causa. Esto nos parece, en cualquier caso, muy grave, más aún tratándose de docentes universitarios que deberían justamente dar lección de responsabilidad - en el más amplio sentido de la palabra - a sus educandos. Ello se hace evidente en los resultados de nuestra encuesta.» Más adelante los autores añaden: «No cabe la menor duda de que en las últimas dos décadas la enseñanza universitaria se ha deteriorado tremendamente y, como es natural, la arqueología no podría ser ajena a este fenómeno. [...] Pero además, hemos podido comprobar que el arqueólogo peruano promedio no tiene costumbre de leer, y que sus lecturas se reducen a unos cuantos títulos. Este no es un defecto sólo de nuestra profesión sino que es un mal nacional, pero no por ello deja de ser un defecto grave. Y uno de los factores que limitan en este sentido a los arqueólogos es la falta de dominio de idiomas. [...] Pero otro grave defecto en la formación del arqueólogo es que no se le enseña a escribir informes. Y de ello resulta que el arqueólogo peruano promedio no publica sus investigaciones. Lo hemos manifestado en otra parte de este estudio, y lo repetimos ahora: El escribir un informe significa tener un entrenamiento especial. Se necesita disciplina de trabajo, adquirir una mentalidad científica, tener familiaridad con el material bibliográfico, etc., y, obviamente, un manejo del idioma. Y todo ello no se adquiere con rapidez, es un trabajo largo, de entrenamiento continuo, que se debería inculcar al alumno a lo largo de sus años de permanencia en la universidad. La tesis debería de ser la culminación de este proceso y es absolutamente necesaria que ella sea restablecida, como una norma obligatoria para poder terminar la carrera» [...] otro hecho de suma gravedad que se ha podido constatar es que [...] El arqueólogo que se dedica a la docencia, sencillamente improvisa y, como lo hemos escuchado decir más de una vez de boca de nuestro colegas, «puede dictar cualquier materia». Y eso de hecho sucede. Y se hace más evidente si se analiza los syllabus de los diferentes planes de estudios. [...] Salvo raras y honrosas excepciones, el docente peruano no prepara sus clases, no hay un análisis bibliográfico concienzudo que permita no solo exponer una materia, sino hacerlo críticamente y tomando posiciones. Y ello, una vez más, se refleja en los syllabus que no se renuevan, y que permanecen iguales a los largo del tiempo que el docente se encarga de una asignatura [...] Si se juntan todos estos problemas, se comienza a desarrollar una cadena interminable de hechos que, en conjunto, agudizan la crisis de la Arqueología Peruana. De esta manera el profesor mediocre en una universidad académica competitiva no tendría muchas posibilidades de hacer carrera universitaria, la cual no existe en nuestro medio y por eso se convierte en un juego de acomodos en los que intervienen muchísimos factores extra o anti-universitarios.» (Bonavia \& Matos 1992: 217-218; 223, 224).

Nadie, a pesar de tener esta evaluación como precedente, ha tratado de enmendar el rumbo de nuestra tan amada carrera. Personalmente creo que la mediocridad, el ser despiadado ocupando un cargo público y aprovecharse del mismo para beneficios personales, es lo que ha venido ganando terreno todo este tiempo. Los valores y el pudor ante la corrupción se han perdido. Hemos llegado a un punto en donde decir la verdad en el Perú es un peligro y nos hemos vuelto insensibles ante estos actos que no son los correctos. Recordemos las propias palabras de Bonavia en un discurso leído en Trujillo en 2011: 
«Si me permiten quisiera ahora dirigirme a los jóvenes estudiantes de arqueología. Y comenzaré recordándoles lo que me dijo Jorge Muelle cuando, hacia la mitad del siglo pasado, fui tímidamente a tocarle la puerta de la dirección del entonces Museo Nacional de Antropología y Arqueología para decirle que había decidido estudiar arqueología y que quería que él me aconsejara. Me miró y lo único que me dijo fue: «Jovencito considere que con la arqueología quizá podrá conseguir un poco de gloria pero nunca dinero. Piénselo, y si decide seguir regrese». Al día siguiente le volví a tocar la puerta. Las palabras del maestro encierran una gran verdad, pero hay que hacer una salvedad. Él se refería a la arqueología seria, a la científica. No a la arqueología «de la gran tumba» o de «liberación» que en esa época no existían y que hoy, por ser rentable, se han convertido en el paradigma de las presentes generaciones que no se dan cuenta de lo negativo que ello es y que en muchos casos, desafortunadamente, es el ejemplo que reciben de sus profesores o de colegas mayores con los que ellos trabajan. Es responsabilidad de los profesores el explicar a sus estudiantes que esa no es la verdadera arqueología. Si se quiere sacar a nuestra disciplina del hoyo en el que está hundiéndose, hay que pedirles a los profesores que sean lo más estrictos que es posible en sus exigencias y a los alumnos que acepten estos tratos conscientes que es para su propio bien. La Arqueología Peruana no necesita una gran cantidad de estudiosos, sino un grupo reducido de ellos pero bien preparado. De arqueólogos que entiendan que nuestra tarea fundamental es la investigación, que la profesión se practica en el terreno y no detrás de un escritorio.» (ms. Bonavia, Discurso leído en Trujillo 28 de febrero del 2011).

No ha sido tarea fácil escribir sobre el humanista de quien guardo en el alma tan gratos recuerdos de enseñanza y amistad que han marcado mi vida. Ha partido un 4 de agosto de 2012; nos ha brindado el ejemplo de trabajo y compromiso con la arqueología peruana, siempre ejerciendo lo que le apasionaba. Hoy he querido con el respeto alturado que merece Duccio Bonavia se conozca parte de su personalidad como profesor e intelectual que con honestidad, seriedad y con la verdad, ha sabido dejarnos sus mejores obras.

Ab imo pectore.

(Desde lo más profundo del corazón)

Lima, 5 de febrero de 2013

\section{BIBLIOGRAFÍA}

BONAVIA, Duccio

1959 «Una semana de arqueología peruana». El Comercio, Suplemento Dominical. Lima, domingo 6 de diciembre de 1959, pp. 11.

1959 «Una pintura mural de Pañamarca, Valle de Nepeña». Arqueológicas 5: 21-53. Publicación del Instituto de Investigaciones Antropológicas. Lima: Museo Nacional de Antropología y Arqueología, Pueblo Libre.

1959 Excavaciones estratigráficas en Ancón (Noviembre-Diciembre).

1960 Sobre el estilo Teatino. Tesis de Bachiller UNMSM, Facultad de Letras, Instituto de Etnología y Arqueología, 1960.

1960 «Alfred Kroeber y su obra peruanista». Revista del Museo Nacional, Tomo XXIX, pp. 292-296.

1963 «En torno a las decoraciones murales». El Comercio, Suplemento Dominical. Lima, 14 de enero de 1963 , pp. 2.

1974 Ricchata Quellccani. Pinturas Murales Prehispánicas. Fondo del Libro del Banco Industrial del Perú.

1982 Precerámico Peruano. Los Gavilanes. Mar, desierto y oásis en la historia del hombre. Corporación Financiera de Desarrollo S.A. Instituto Arqueológico Alemán. Lima.

1985 Mural Painting in Ancient Peru. Publisher, Indiana University press.

2002-2004 «Jorge Muelle: Semblanza del hombre y del Arqueólogo». Revista Histórica, Tomo XLI, pp. 213-219.

2005-2006 «La arqueología Peruana en el siglo XX». Revista Histórica, Tomo XLII, pp. 145-170. 
2007 «Fernando Silva Santiesteban in memoriam». La insignia, pp 1-3. [En línea] < www.lainsignia. org/2007/febrero/cul_017.htm> [Acceso el 26 marzo de 2011].

2008 El Maíz. Su origen, su domesticación y el rol que ha cumplido en el desarrollo de la cultura. Universidad de San Martín de Porres, Fondo Editorial. Escuela Profesional de Turismo y Hotelería.

2010 «La domesticación de las plantas». Cátedra Julio Cesar Tello. Museo de Arqueología y Antropología de la Universidad Nacional Mayor de San Marcos. Lima, pp. 53-64.

2011 Discurso leído en Trujillo, 28 de febrero del 2011.

BONAVIA, Duccio; Ramiro MATOS

1992 La enseñanza de la arqueología en el Perú. Informe Evaluativo. Lima: Fomciencias.

BORDES François

1981 Typologie du Paleolithique Ancient et Moyen. Cahiers du Quaternaire 1

DILLEHAY, Tom

1976 Competition and cooperation in a prehispanic multietnic system in the Cental Andes. Thesis published on demand by: University Microfilms international Ann Arbor, Michigan, USA.

FUNG, Rosa

1963 «Las Decoraciones Murales y el Deber de Preservarlas». Dominical, Suplemento de El Comercio. Lima 13 de enero de 1963, pp.2

MATOS, José; José DEUSTUA y José RÉNIQUE

1981 Luis E. Valcárcel. Memorias. Lima: Instituto de Estudios Peruanos.

MATOS, Ramiro (editor)

1960 Antiguo Perú, espacio y tiempo. Lima: Libreria Editorial Juan Mejia Baca, 400 p.

SILVA, Fernando

2007 «Duccio Bonavia». Arqueología y Vida 1: 39-44.

SONNEVILLE-BORDES D.de, PERROT J.

1956 «Lexique typologique Du Paleolithique Superior». Bulletin de La Société Préhistorique Française. Vol. 53: 408-412.

TABío, Ernesto

1962 Correspondencia enviada desde Cuba a Duccio Bonavia, 14 octubre de 1962. Manuscrito.

1966 Correspondencia enviada desde Cuba a Duccio Bonavia, 18 de Octubre de 1966. Manuscrito.

1969 Historia Antigua de la Costa Peruana (Época Prehispánica). Tesis doctoral, inédita. La Habana Academia de Ciencias de Cuba.

WILLEY, Gordon

1953 Prehistoric Settlement Patterns In The Virú Valley, Perú. Smithsonian Institution Bureau Of American Ethnology. Bulletin155. 